\title{
HIV and venous thromboembolism risk: Report of 3 cases with review of the literature
}

\author{
Mohamed El Amraoui, Rachid Frikh, Naoufal Hjira, Mohammed Boui
}

\author{
Dermatology-Venereology Department, Mohammed V Military Teaching Hospital, Rabat, Morocco
}

Corresponding author: Dr. Mohamed El Amraoui, E-mail: med.elamraoui.dto@gmail.com

\begin{abstract}
Thromboembolic disease is particularly increased in HIV-infected patients for multiple reasons as shown by several recent studies. We present three cases with literature review. Case 1: Young patient followed for HIV infection with poor treatment adherence, presented with febrile dyspnea with acute chest pain, radiography and chest CT were in favor of pulmonary embolism, the evolution was favorable with anticoagulants. Case 2: young patient admitted to the emergency department for thrombophlebitis of the lower limb with cachexia and alteration of the general state whose etiological assessment was in favor of an HIV infection, the evolution was favorable under tritherapy and anticoagulants. Case 3: young patient followed for HIV infection, had an active lengthening of cephalin time with hyperfibrinogenemia and the presence of antiphospholipid antibodies (lupus anticoagulant), the evolution was favorable under platelet antiaggregants. The risk of thromboembolism especially venous is serious and must be integrated into the overall care of patients.
\end{abstract}

Key words: HIV; AIDS; Thromboembolism; Venous

\section{INTRODUCTION}

HIV infection, with about 37 million cases globally and 22000 nationally, is a major health problem. Thromboembolic disease is increasingly reported during infection with the HIV. It interests the venous territory with predilection. We present three cases with review of the literature.

\section{CASE REPORT}

\section{Case 1}

A 40-year-old man, followed for retroviral infection for 8 years, with poor treatment adherence, was admitted for febrile dyspnea. Chest X-ray showed well-circumscribed right basal opacity and thoracic CT was in favor of massive, bilateral pulmonary embolism with infarction and superinfection of the right lower lobe (Figs. 1, 2a-2b). The patient was put under a treatment based on antibiotics and anticoagulants with a favorable evolution over two years of decline.

\section{Case 2}

A 50-year-old patient with a history of repeated STIs was hospitalized for left femoro-popliteal thrombophlebitis with cachexia and general impairment. The report showed a retroviral infection at the AIDS stage. The patient was put under tritherapy and anticoagulants with a favorable evolution over two years of decline.

\section{Case 3}

55 year old man, followed for retroviral infection at the AIDS stage under triple therapy. Presented an elongated Activated Cephalin Time, hyperfibrinogemia with presence of an anti-phospholipid antibody (lupus anticoagulant). The patient was placed on platelet antiaggregants with a favorable evolution over two years of decline.

\section{DISCUSSION}

The risk of venous thromboembolism in HIV-infected patients has been described since the 1990s and it's 2

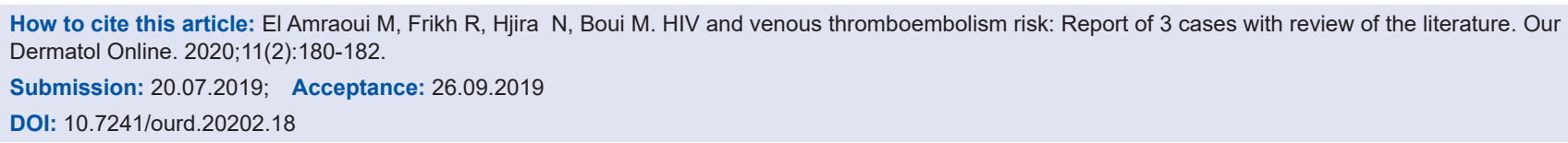




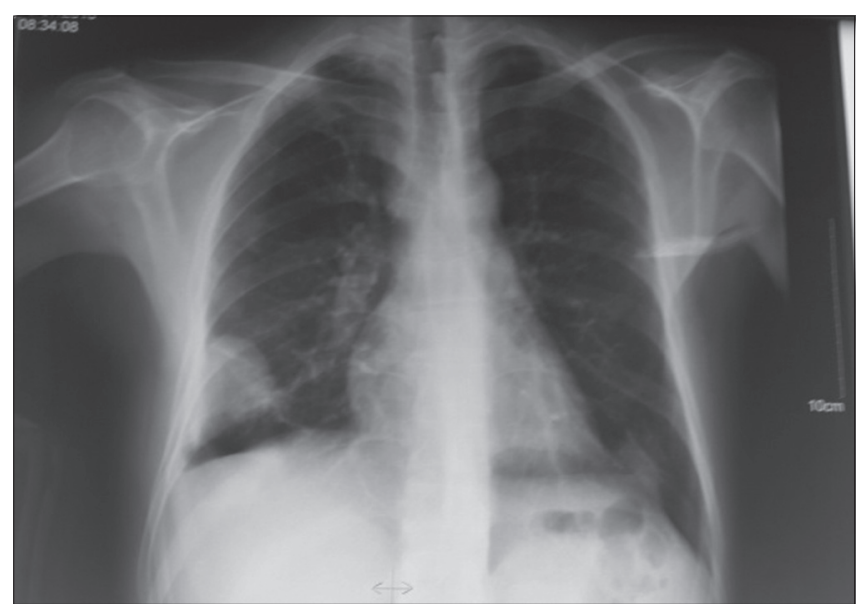

Figure 1: Chest X-ray showing well-circumscribed right basal opacity.

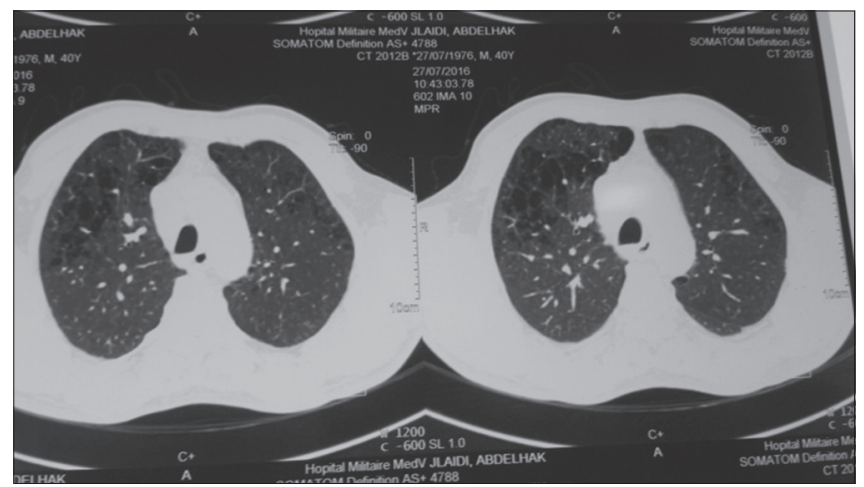

Figure 2a: Thoracic CT showing massive and bilateral pulmonary embolism with superinfection of the lower right lobe.

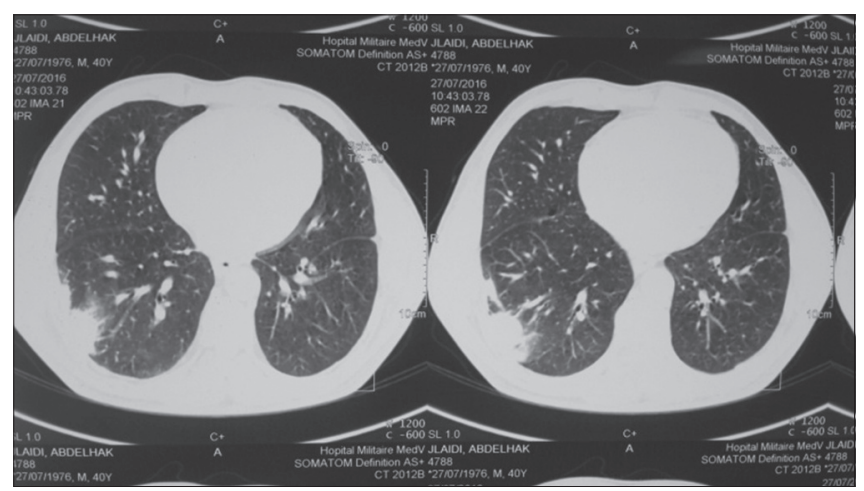

Figure 2b: Thoracic CT showing massive and bilateral pulmonary embolism with superinfection of the lower right lobe.

to 10 times higher than in the general population with a frequency that varied between studies between $0.19 \%$ and $7.63 \%[1,2]$.

The most frequent venous thromboembolic events are the lower limbs and pulmonary arteries, other rarer localizations are the portal vein and the renal veins, however other unusual localizations have been described, particularly in patients with hemostasis disorders (brain, mesenteric and retinal thrombophlebites) [2,3].

This prothrombotic state is multifactorial and favored by: a low level of CD4, the presence of a detectable viral load, the presence of opportunistic infections and neoplasias, iatrogenic factors such as antiproteases, excess of samples and surgery, abnormalities of the hemostasis such as excess thrombogenic factors, decreased coagulation inhibitors and fibrinolysis in addition to endothelial damage. These promoting factors have not only an additional but synergistic and exponential effect [2]. Also, there are drug interactions between antiretrovirals including antiproteases and drugs acting on hemostasis (anticoagulants, platelet antiagregants), these interactions can be activating or inhibiting with the risk of thromboses and hemorrhages, hence the interest of careful and rigorous supervision, without forgetting the relative frequency of Heparininduced thrombocytopenia in seropositive patients.

So, physicians who care for HIV-positive patients must not only be careful to watch for and treat infectious complications and neoplasias, but they must be equally attentive to the risk of thromboembolism especially venous but also arterial. It would then be justifiable to raise the possibility of pulmonary embolism in the event of any dyspnea in the seropositive patient and to ask for an HIV serology in case of any thromboembolic disease in the young subject without favoring thromboembolic factors.

\section{CONCLUSION}

HIV infection is a risk factor for venous thromboembolic complications for many reasons. Antiretrovirals have significantly improved the prognosis of this particular infection, but at the cost of complications including thrombogenic terrain and direct thrombogenic risk of anti proteases. This dimension must be taken into consideration in the management of seropositive patients.

\section{Consent}

The examination of the patient was conducted according to the Declaration of Helsinki principles.

\section{REFERENCES}

1. Tazi-Mezalek Z, Alaoui-Bennasser H, Maamar M, Harmouche H, Adnaoui M. Thrombose et infection à VIH: à propos de 10 cas. J Malad Vasculair. 2014;39:351-2.

2. Bibas M, Biava G, Antinori A. HIV-Associated Venous Thromboembolism. Mediterr J Hematol Infect Dis. 2011;3:e2011030. 
www.odermatol.com

3. Ahonkhai AA, Gebo KA, Streiff MB, Moore RD, Segal JB. Venous Thromboembolism in Patients with HIV/AIDS A Case-Control Study. J Acquir Immune Defic Syndr. 2008;48:310-4.

4. Singer EJ, Valdes-Sueiras M, Commins DL, Yong W, Carlson M. HIV stroke risk: evidence and implications. Ther Adv Chronic Dis. 2013;4:61-70.
Copyright by Mohamed El Amraoui, et al. This is an open-access article distributed under the terms of the Creative Commons Attribution License, which permits unrestricted use, distribution, and reproduction in any medium, provided the original author and source are credited.

Source of Support: Nil, Conflict of Interest: None declared. 